$\begin{array}{lll}\text { ISSN:1991-8178 } & \text { APPLIED SCIENCES } \\ \text { EISSN: } 2309-8414 & \text { AOI: } 10.22587 / \text { ajbas.2017.11.16.9 } \\ \text { Journal home page: www.ajbasweb.com } & \text { Basic and Applied Sciences }\end{array}$

\title{
Effect Of Cigarette Smoking And Physical Exercise On Some Hematological Parameters In Healthy Students
}

Noor Al-Taee

Noor Al-Taee, assistant lecturer, Department of biology, Faculty of Science and Health,, University of Koya, Koisanjaq, Erbil, Iraq.

\section{Address For Correspondence:}

Noor Al-Taee, University of Koya, Department of Biology, Faculty of Science and Health, Erbil. Iraq.

E-mail:noor.subhy@koyauniversity.org.

\section{ARTICLE INFO}

Article history:

Received 12 October 2017

Accepted 22 December 2017

Available online 31 December 2017

Keywords:

Cigarette smoking, young smokers, hematological parameters, physical exercise, healthy smoker, sport exercise.

\begin{abstract}
A B S T R A C T
Background: Physical exercise is a good, but smoking a cigarette at the end of exercise detracts from achievements and harms the body. Objective: Tobacco cigarette smoking is one of the major leading causes of death throughout the world. This study has been conducted to determine the impact of sport exercise on hematological parameters in young smokers. Results: The study was applied on (60) blood samples of physical education students and medical microbiology students at aged (18-25). The students divided into two groups (30/group). The first group (non-athletes group) was divided into two subgroups: Smokers and non-smokers. The second group (athletes group) also divided into two subgroups: Smokers and non-smokers. The result show no significant difference ( $>0.05$ ) of white blood cell (WBC), red blood cell (RBC), and hematocrit $(\mathrm{PCV})$, mean corpuscular volume (MCV), mean corpuscular hemoglobin $(\mathrm{MCH})$ and mean corpuscular hemoglobin concentration (MCHC). But we find significant difference $(\mathrm{p}>0.05)$ in hemoglobin $(\mathrm{Hb})$ and platelets (PLT), between non-athletes smokers and non-athletes nonsmokers. The result also show no significant difference $(\mathrm{p}>0.05)$ of $(\mathrm{WBC}),(\mathrm{RBC}),(\mathrm{Hb}),(\mathrm{PCV}),(\mathrm{MCV}),(\mathrm{MCH})$ and $(\mathrm{MCHC})$. But there is a significant difference ( $p>0.05)$ in (PLT), between non-athletes smokers and athletes smokers. Conclusion: As per the results obtained in our study and in the light of the above discussion it can be concluded that continue smoking for long periods affect the blood components especially with the increase in age. Also the regular exercise help reduce the free radicals which formed in the body after the constant smoking.
\end{abstract}

\section{INTRODUCTION}

The research included a study the effect of cigarette smoking and regular exercise on the some hematological parameters among smoker students. This study has been conducted to determine the impact of sport exercise on hematological parameters in young smokers.

\section{Introduction-Review:}

Smoker knows that he is the person who smoked more than ten cigarettes per day (Mahapatra and Roy, 2008). Tobacco cigarette smoking is one of the major leading causes of death and essential public health challenge in world over (Kume et al., 2009). Smoking has both acute and chronic effect on hematological parameter of blood. Smoking is considered to cause cancer; stroke and heart dis-ease (Ishizaka et al., 2007). There are more than 4000 chemicals found in cigarette smoke (Green and Rodgman, 1996), and a cigarette smoker is exposed to a number of harmful substances including nicotine, free radicals, carbon monoxide and other gaseous products (Gitte, 2011). It is widely known that smokers have higher risk for cardiovascular diseases, hypertension, inflammation, stroke, clotting disorder, and respiratory disease (Abel et al., 2005; -Tiel et al., 2002). Cigarette smoke is an important factor in the formation of free radicals Chow, 1993). Can distinguishing two phases in the process of cigarette smoke are tar and gas phase (Pasupathi, 2009). Found

Open Access Journal

Published BY AENSI Publication

(C) 2017 AENSI Publisher All rights reserved

This work is licensed under the Creative Commons Attribution International License (CC BY).

http://creativecommons.org/licenses/by/4.0/

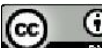

Open Access

To Cite This Article: Noor Al-Taee., Effect Of Cigarette Smoking And Physical Exercise On Some Hematological Parameters In Healthy Students. Aust. J. Basic \& Appl. Sci., 11(16):62-68, 2017 
from the analysis of each phase that one puff cigarette contains about 1014 free radical in the tar phase and 1015 free radical in gas phase to be in the form of different com-pounds capable of causing increased generate different types of Reactive Oxygen Species (ROS) such as Superoxide (O2.-), Hydrogen peroxide (H2O2), Hydroxyl (OH.) and Peroxyl (ROO.). These ROS in turn able to generate oxidative damage in the form of lipid peroxidation (Pasupathi, 2009). That ROS contribute in many metabolic processes and transfers of cellular signal and is believed to have an important impact on premature aging, so the removal of toxicity and disposal is essential for the physiological activity of living cells (Goraca and Skibska, 2005). Living organisms able to develop complex systems as antioxidants to equation ROS and to reduce the harm caused and these systems it is ether enzymatically like, superoxide dismutase, catalase and glutathione peroxidase, or large molecules such as ferritin, ceruloplasmin and albumin, or various types of small molecules such as ascorbic acid, reduced glutathione, $\beta$-carotene, $\alpha$-tocopherol, bilirubin, uric acid and methionine (Goraca and Skibska, 2005). The body uses antioxidants to soak up free radicals like sponges. If your body has plenty of antioxidants available, it can minimize the damage caused by free radicals. Under normal physiological conditions, there is a critical balance in the generation of oxygen free radicals and antioxidant defense systems used by organisms to deactivate and protect themselves against free radical toxicity (Halliwell, 1998). Exercise is an important function of living systems. It affects many systems in our body. Human body adapts to exercise by breathing and by cardiovascular systems; such as, cardiac output is 20-25 liters during high intensity exercise (Foss and Keteyian, 1998) and also exercise may affect blood parameters. Physical and physiological response also plays an important role, in hematology (Astrand, and. Rodalf, 1986). When hematology is analyzed, the effect of acute exercise on hematological levels is seen different. It is stated that these differences depend on the severity, duration, exercise at different times of day and frequency of exercise as well as physical and physiological conditions of subjects (Koc et al., 2012). Because of the impact of the positive useful for exercise by increasing the energy level in the body and thus increase the capacity of organs of the body to absorb nu-trients more effectively, leading to a balance of high blood pressure and increased heart and lungs activity and increase the speed of the circulatory system (William et al., 2000) and the prevention of obesity, diabetes, cancer and diseases respiratory and Osteoporosis, heart disease and blood vessels and maintain health and fitness (Bloomer et al., 2005).

\section{MATERIAL AND METHODS}

Sixty blood samples collected from physical education students and students of medical microbiology Dept. $\backslash$ Faculty of Science and Health\Koya University-Iraq's Kurdistan region, at aged (18-25 years) and with good health. Samples divided into two main groups as follows:

First group (non-athletes group) 30 students were divided into two subgroups: 15 smokers and 15 nonsmokers.

Second group (athletes group) 30 students were divided into two subgroups: 15 smokers and 15 nonsmokers.

\section{Laboratory test:}

Data were subjected to analysis of version (ANOVA) using SPSS program. The Hematological values between smokers and non-smokers, athletes and non- athletes were compared using unpaired " $t$ " test. $\mathrm{P}<0.05$ was considered for statistically significance (Rosner, 2000).

\section{Statistical analysis:}

Data were subjected to analysis of version (ANOVA) using SPSS program. The Hematological values between smokers and non-smokers, athletes and non- athletes were compared using unpaired " $t$ " test. $\mathrm{P}<0.05$ was considered for statistically significance (Rosner, 2000).

\section{RESULT AND DISCUSSION}

The results showed no significantly high in the level of WBC $(\mathrm{p}>0.05)$ in non-athletes smokers compared with non-athletes non-smokers. The results showed a significantly high in eosinophil (EOS) and no significant in neutrophil (NEU), while there was a significantly low in monocyte (MON) and no significantly in lymphocyte (LYM). This result consistent with (Higuchi et al., 2016) where noted increased total leukocyte count observed in smokers. Also the result show no significantly high in RBC, significantly high in $\mathrm{Hb}$ and PLT and no significantly low in PCV, MCV, MCH and MCHC Table (1)these result consistent with (Malenica et al., 2017) where noted increased total leukocyte count observed in smokers. These results are inconsistent with (Brun, et al., 1998) where noted a significantly high in the level of WBC in male smokers are also inconsistent with (Asif1 et al., 2013) where noted a significantly high in RBC, Hb and PCV and no significant 
differences in PLT. While the results were consistent with [18] that there are no significant differences in the level MCV wile inconsistent with (Brun, et al., 1998)where noted a significantly low in MCH and MCHC.

Table 1: Effect of smoking on hematological parameters in non-athlete's students

\begin{tabular}{|c|c|c|c|}
\hline No. & Parameters & $\begin{array}{l}\text { Non-Athletes } \\
\text { Non-Smokers } \\
(\mathrm{n}=15) \\
\text { Mean } \pm \text { SD }\end{array}$ & $\begin{array}{l}\text { Non-Athletes } \\
\text { Smokers } \\
(\mathrm{n}=15) \\
\text { Mean } \pm \mathrm{SD} \\
\end{array}$ \\
\hline 1. & WBC $\left(10^{3} \backslash \mu 1\right)$ & $6.61 \pm 2.55$ & $7.20 \pm 1.80$ \\
\hline 2. & LYM $(\%)$ & $34.28 \pm 4.99$ & $31.21 \pm 6.76$ \\
\hline 3. & MON (\%) & $5.72 \pm 2.06$ & $5.37 \pm 1.13^{*}$ \\
\hline 4. & NEU $(\%)$ & $37.47 \pm 2.13$ & $39.23 \pm 3.11$ \\
\hline 5. & EOS (\%) & $22.60 \pm 3.78$ & $23.80 \pm 4.83^{*}$ \\
\hline 6. & BAS (\%) & $0.00 \pm 0.00$ & $0.47 \pm 0.52$ \\
\hline 7. & $\operatorname{RBC}\left(10^{3} \mid \mu 1\right)$ & $5.21 \pm 0.79$ & $5.74 \pm 0.71$ \\
\hline 8. & $\mathrm{Hb}(\mathrm{g} \backslash \mathrm{dl})$ & $15.73 \pm 0.69$ & $14.37 \pm 2.05^{* *}$ \\
\hline 9. & PCV (\%) & $47.57 \pm 2.16$ & $46.47 \pm 3.05$ \\
\hline 10. & MCV (fl) & $90.13 \pm 8.81$ & $81.80 \pm 9.69$ \\
\hline 11. & $\mathrm{MCH}(\mathrm{pg})$ & $30.75 \pm 4.43$ & $25.07 \pm 3.52$ \\
\hline 12. & MCHC (g\dl) & $33.10 \pm 0.32$ & $30.98 \pm 4.16$ \\
\hline 13. & PLT $\left(10^{3} \backslash \mu 1\right)$ & $270.00 \pm 53.00$ & $268.87 \pm 96.55^{* *}$ \\
\hline
\end{tabular}

Although strong epidemiological evidence links cigarette smoking to cardiovascular disease, cancer and chronic obstructive pulmonary disease (COPD), the exact mechanisms of these links remain poorly understood.

Some of the adverse effects of smoking include: initiation of endothelial injury (Pittilo, 2000), acceleration of coronary progression and new lesion formation (Waters et al., 1996) and overall alterations in lipid and hemostatic systems (Tsiara et al., 2003). Detecting endothelial damage may be the most useful step in the early diagnosis of atherosclerosis. Although the endothelium releases many molecules into the circulation and arterial wall, not all of them are specific to the endothelium and are therefore of limited research or diagnostic potential (Blann and Lip, 1998). The mechanism for smoking-induced increase in WBC count is not clear. It has been suggested that inflammatory stimulation of the bronchial tract induces an increase in inflammatory markers in the blood but it has also been suggested that nicotine may induce an increase in blood lymphocyte counts (Calapai et al., 2009). While leukocytosis may simply be a marker of smoking-induced tissue damage, the high count can promote cardiovascular diseases through multiple pathologic mechanisms that mediate inflammation, plug the microvasculature, induce hypercoagulability and promote infarct expansion (Geffken et al., 2001) .In fact several studies have shown that WBC count is an independent predictor of atherosclerosis and cardiovascular disease (Geffken et al., 2006). The high WBC count in our male smoking subjects may also suggest that they might be at greater risk for developing atherosclerosis and cardiovascular diseases than non-smokers.

The reported refer that high level RBC, WBC and Hematocrit are associated with blood viscosity and clotting in smokers (Ho, 2004). High level of RBC is termed as polycythemia and very high RBC mass slows blood velocity and increase the risk of intravascular clotting, coronary vascular resistance, decreased coronary blood flow, and a predisposition to thrombosis (Ravala and Paula, 2010). It has been established that fibrinogen levels are higher in smokers than in non-smokers, and it has been estimated that the increasing risk of cardiac disease in smokers may be associated with high fibrinogen levels through arterial wall infiltration and effects on blood viscosity, platelet aggregation, and fibrin formation (Hunter, 2001).

This elevation may lead to congenital heart disease, pulmonary fibrosis and elevated erythropoietin (Milman and Pedersen, 2009). The mechanism by which polycythemia causes thrombosis is still under investigation, but smoking cigarettes creates a unique condition of combined polycythemia to chronic hypoxia, leading to elevated red cell production due to an elevated carboxyhemoglobin level, with concomitant plasma volume reduction. Overall, thrombosis is a serious complication of polycythemia and can lead to death in up to $8.3 \%$ of patients (Ferro, 2004).

$\mathrm{MCV}, \mathrm{MCH}$ and $\mathrm{MCHC}$ are three main red blood cell indices that help in measuring the average size and hemoglobin composition of the red blood cells. Their values are derived from the Hb, HCT and RBCcount by mathematical calculations. MCV indicates the size of a red blood cell and presence of red cells smaller or larger than normal size means the person has anemia, elevated levels of MCV in our study indicates that subjects might suffer from megaloblastic, hemolytic, pernicious or macrocytic anemia usually caused by iron and folic acid deficiencies. $\mathrm{MCH}$ is the average weight of hemoglobin that is present inside single red blood cell whereas MCHC denotes the amount of hemoglobin in a specific volume of 'packed' red corpuscles or cells. We found no significantly low value of MCHC $(\mathrm{p}<0.05)$ among smokers indicating 
hypochromic anemia and might be due to paucity of folic acid or vitamin B12 or thyroid problems. (Ghosh et al., 2012).

The results also showed no significantly high in the level of WBC ( $>0.05)$ in athletes smokers compared with athletes non-smokers. The results showed a significantly high in EOS and NEU, while there was a significantly low in MON and LYM. Also the result show no significantly low in RBC and PLT, no significantly high in $\mathrm{Hb}, \mathrm{PCV}, \mathrm{MCH}$ and $\mathrm{MCHC}$ wile significantly high in MCHC Table (2).

Table 2: Effect of smoking on hematological parameters in athlete's students

\begin{tabular}{|l|l|l|l|}
\hline No. & Parameters & $\begin{array}{l}\text { Athletes } \\
\text { Non-Smokers } \\
(\mathrm{n}=15) \\
\text { Mean } \pm \text { SD }\end{array}$ & $\begin{array}{l}\text { Athletes } \\
\text { Smokers } \\
(\mathrm{n}=15) \\
\text { Mean } \pm \text { SD }\end{array}$ \\
\hline 1. & & $4.74 \pm 4.82$ & $7.28 \pm 6.55$ \\
\hline 2. & WBC $\left(10^{3} \backslash \mu \mathrm{l}\right)$ & $29.23 \pm 2.01$ \\
\hline 3. & LYM $(\%)$ & $40.34 \pm 0.96$ & $4.83 \pm 0.79$ \\
\hline 4. & MON (\%) & $7.45 \pm 1.87$ & $44.20 \pm 6.17$ \\
\hline 5. & NEU (\%) & $41.70 \pm 3.45$ & $21.74 \pm 4.28$ \\
\hline 6. & EOS $(\%)$ & $10.59 \pm 2.29$ & $0.00 \pm 0.00^{*}$ \\
\hline 7. & BAS $(\%)$ & $0.02 \pm 0.41$ & $4.98 \pm 0.41$ \\
\hline 8. & RBC $\left(10^{3} \backslash \mu 1\right)$ & $5.23 \pm 0.53$ & $15.99 \pm 0.77$ \\
\hline 9. & Hb $(\mathrm{g} \backslash \mathrm{dl})$ & $15.65 \pm 0.76$ & $46.61 \pm 1.38$ \\
\hline 10. & PCV $(\%)$ & $46.05 \pm 2.56$ & $94.36 \pm 6.35^{*}$ \\
\hline 11. & MCV $(\mathrm{fl})$ & $77.33 \pm 16.70$ & $32.55 \pm 2.76^{*}$ \\
\hline 12. & $\mathrm{MCH}(\mathrm{pg})$ & $26.35 \pm 6.57$ & $34.43 \pm 1.61$ \\
\hline 13. & $\mathrm{MCHC}(\mathrm{g} \backslash \mathrm{dl})$ & $33.98 \pm 1.24$ & $211.73 \pm 2.37$ \\
\hline
\end{tabular}

* Significant ${ }^{* *}$ High significant

The results showed no significantly high in the level of WBC ( $p>0.05)$ in non-smokers athletes compared with non-smokers non-athletes. The results showed a significantly high in LYM, and no significantly in MON and NEU. While there was no significantly low in EOS. Also the result show no significantly high in RBC and MCHC, no significantly low in Hb, PCV, MCV, MCH and PLT Table (3).

Table 3: Effect of sport exercise on hematological parameters in non-smoker's students

\begin{tabular}{|c|c|c|c|}
\hline No. & Parameters & $\begin{array}{l}\text { Non-Smokers } \\
\text { Non-Athletes } \\
(\mathrm{n}=15) \\
\text { Mean } \pm \text { SD }\end{array}$ & $\begin{array}{l}\text { Non-Smokers } \\
\text { Athletes } \\
(\mathrm{n}=15) \\
\text { Mean } \pm \mathrm{SD}\end{array}$ \\
\hline 1. & WBC $\left(10^{3} \backslash \mu 1\right)$ & $6.61 \pm 2.55$ & $4.74 \pm 0.48$ \\
\hline 2. & LYM (\%) & $34.28 \pm 4.99$ & $40.34 \pm 0.96^{*}$ \\
\hline 3. & MON (\%) & $5.72 \pm 2.11$ & $7.45 \pm 1.87$ \\
\hline 4 & NEU (\%) & $37.47 \pm 2.14$ & $41.70 \pm 3.45$ \\
\hline 5. & EOS (\%) & $22.60 \pm 3.78$ & $10.58 \pm 2.29$ \\
\hline 6. & BAS (\%) & $0.00 \pm 0.00$ & $0.20 \pm 0.041^{*}$ \\
\hline 7. & $\operatorname{RBC}\left(10^{3} \backslash \mu 1\right)$ & $5.21 \pm 0.79$ & $5.23 \pm 0.53$ \\
\hline 8. & $\mathrm{Hb}(\mathrm{g} \backslash \mathrm{dl})$ & $15.73 \pm 0.69$ & $15.65 \pm 0.76$ \\
\hline 9. & $\mathrm{PCV}(\%)$ & $47.57 \pm 2.16$ & $46.05 \pm 2.56$ \\
\hline 10. & MCV (fl) & $90.13 \pm 8.81$ & $77.33 \pm 16.70$ \\
\hline 11. & $\mathrm{MCH}(\mathrm{pg})$ & $30.75 \pm 4.43$ & $26.35 \pm 6.57$ \\
\hline 12. & MCHC (g\dl) & $33.10 \pm 0.32$ & $33.98 \pm 1.24$ \\
\hline 13. & $\operatorname{PLT}\left(10^{3} \backslash \mu 1\right)$ & $270.00 \pm 53.00$ & $245.33 \pm 21.62$ \\
\hline
\end{tabular}

The results showed no significantly high in the level of WBC ( $p>0.05)$ in smokers athletes compared with smokers non-athletes. The results showed no significantly low in LYM, MON and EOS. While there was no significantly high in NEU. Also the result show no significantly low in RBC and significantly in PLT, and there was no significantly high in $\mathrm{Hb}, \mathrm{PCV}, \mathrm{MCV}, \mathrm{MCH}$ and $\mathrm{MCHC}$ Table (4). 
Table 4: Effect of sport exercise on hematological parameters in smoker's students

\begin{tabular}{|c|c|c|c|}
\hline No. & Parameters & $\begin{array}{l}\text { Smokers } \\
\text { Non-Athletes } \\
(n=15) \\
\text { Mean } \pm \text { SD }\end{array}$ & $\begin{array}{l}\text { Smokers } \\
\text { Athletes } \\
(n=15) \\
\text { Mean } \pm \text { SD }\end{array}$ \\
\hline 1. & WBC $\left(10^{3} \backslash \mu 1\right)$ & $7.20 \pm 1.80$ & $7.28 \pm 0.66$ \\
\hline 2. & LYM (\%) & $31.20 \pm 6.76$ & $29.23 \pm 2.01$ \\
\hline 3. & MON (\%) & $5.37 \pm 1.13$ & $4.83 \pm 0.79$ \\
\hline 4. & NEU (\%) & $39.23 \pm 3.11$ & $44.20 \pm 6.17$ \\
\hline 5. & EOS (\%) & $23.80 \pm 4.83$ & $21.74 \pm 4.28$ \\
\hline 6. & BAS (\%) & $0.200 \pm 0.41$ & $0.00 \pm 0.00$ \\
\hline 7. & $\operatorname{RBC}\left(10^{3} \backslash \mu 1\right)$ & $5.74 \pm 0.71$ & $4.98 \pm 0.41$ \\
\hline 8 & $\mathrm{Hb}(\mathrm{g} \backslash \mathrm{dl})$ & $14.37 \pm 2.05$ & $15.99 \pm 0.77$ \\
\hline 9. & PCV (\%) & $46.47 \pm 3.05$ & $46.61 \pm 1.38$ \\
\hline 10. & MCV (fl) & $81.80 \pm 9.69$ & $94.36 \pm 6.35$ \\
\hline 11. & $\mathrm{MCH}(\mathrm{pg})$ & $25.07 \pm 3.52$ & $32.55 \pm 2.76$ \\
\hline 12. & MCHC (g\dl) & $30.98 \pm 4.16$ & $34.43 \pm 1.61$ \\
\hline 13. & $\operatorname{PLT}\left(10^{3} \backslash \mu 1\right)$ & $268.87 \pm 96.55$ & $211.73 \pm 2.37^{* *}$ \\
\hline
\end{tabular}

There is a body of literature on blood rheology and exercise (Wood, 1994), but the conclusions have not been univocal (Moxley et al., 1970). In this study, we examined the hypothesis that exercise has the same effect on rheological parameters of smokers and non-smokers. We found that submaximal exercise is associated with alterations in blood rheology in both smokers and non-smokers. Triphasic rheological changes had been described following exercise (Brun, et al., 1998).

The increase in white blood cell count observed in both smokers and non-smokers following exercise is in line with existing literature where both white cell activation and oxidant stress were implicated in the hemorheological effects of exercise (Gurcan et al., 1998). The increase in the number of leukocytes after exercise may be explained by the increase in blood flow which recruits leukocytes from the marginal pool and/or hormonal changes, which are likely to be mediated by $\beta$ adrenergic receptors. In addition, a decrease in leukocyte filterability, an indication of leukocyte activation during exercise, has also been reported as a likely mechanism for the rise in white cell count (Brun, 2002).

\section{Conclusion:}

From the present study, we can concluded that continuous cigarette smoking increases RBC count, Hb concentration, PCV, WBC count, MCV and $\mathrm{MCH}$ concentration and these alterations might be associated with a greater risk for developing atherosclerosis and cardiovascular diseases. As per the results obtained in our study and in the light of the above discussion it can be concluded that continue smoking for long periods affect the blood components especially with the increase in age. Also the regular exercise help reduce the free radicals which formed in the body after the constant smoking.

\section{ACKNOWLEDGEMENT}

I thank all subjects who helped me in the study, as well as to the biology and medical microbiology staff from the Faculty of Science and Health, Koya University and Large Hospital in Koisanjaq, Erbil, Iraq, who assisted in the study.

\section{Conflict of Interest:}

Authors have no conflict of interest to declare.

\section{REFERENCES}

Abel, G.A., J.T. Hays, P.A. Decker, G.A. Croghan, D.J. Kuter, et al., 2005. Effects of biochemically confirmed smoking cessation on white blood cell count. Mayo Clin Proc, 80(8): 1022-1028.

Asif1, M., S. Karim, Z. Umar, A. Malik, T. Ismail, A. Chaudhary, M.H. Alqahtani and M. Rasool, 2013. Effect of cigarette smoking based on hematological parameters: comparison between male smokers and nonsmokers. Turk J Biochem, 38(1): 75-80.

Astrand, P.O., K. Rodalf, 1986. Textbook of Work Physiology Physiological Bases of Exercise, McGrawHill Book Company, New York, USA., pp: 713-716.

Blann, A.D., G.Y. Lip, 1998. The endothelium in atherothrombotic disease: assessment of function, mechanisms and clinical implications. Blood Coagul Fibrinolysis, 9: 297-306. 
Bloomer, R.J., A.H. Goldfarb, L. Wideman, M.J. McKenzie, L.A. Consitt, 2005. "Effect of acut aerobic and anaerobic exercise on blood markersof oxidative stress" J.Strengh Cond. Res., 19(2): 276-85.

Brun, J.F., S. Khaled, E. Raynaud, D. Bouix, J.P. Micallef, A. Orseti, 1998. Thetriphasic effects of exercise on blood rheology: which relevance to physiology and pathophysiology? ClinHemorheolMicrocirc, 19(2): 89-104.

Brun, J.F., 2002. Exercise haemorheology as a three acts play with metabolic actors: Is it of clinical relevance? Clin Hemorheol Microcirc, 26: 155-174.

Calapai, G., A.P. Caputi, C. Mannucci, A.G. Russo, E. Gregg, R. Puntoni, F. Lowe, M. McEwan, A. Bassi, S. Morandi and A. Nunziata, 2009. Cardiovascular biomarkers in groups of established smokers after a decade of smoking. Basic \& Clinical Pharmacology \& Toxicology, 104: 322-328.

Chow, C.K., 1993. Cigarette smoking and oxidative damage in the lung. Ann. N. Y. Acad. Sci., 686: 289298.

Ferro, J.M., P. Canhao, J. Stam, M.G. Bousser, F. Barinagarrementeria, 2004. ISCVT Investigators: Prognosis of cerebral vein and dural sinus thrombosis: results of the international study on cerebral vein and dural sinus thrombosis (ISCVT). Stroke, 35: 664-670.

Foss, M.L. and S.J. Keteyian, Fox's, 1998. Physiological Basis for Exercise and Sports. Sixth Edition, WCB/McGraw-Hill Book Company, USA..

Geffken, D., M. Cushman, G.L. Burke, J.F. Polak, P.A. Sakkinen, R.P. Tracy, 2001. Association between physical activity and markers of inflammation in a healthy elderly population. Am J Epidemiol., 153: 242-250.

Ghosh, A., S.D. Chowdhury, T. Ghosh, 2012. Undernutrition in Nepalese children: a biochemical and haematological study. ActaPaediatr, 101(6): 671-676.

Gitte, R.N., 2011. Effect of cigarette smoking on plasma fibrinogen and platelet count. Asian Journal of Medical Sciences., 2: 181-184.

Goraca, A. and B. Skibska, 2005. Plasma antioxidant status in healthy smoking and non-smoking men. Bratisl.Lek.Listy, 106(10): 301-306.

Green, C.R., A. Rodgman, 1996. The tobacco chemists' research conference: a half century forum for advances in analytical methodology of tobacco and its products. Recent Adv Tobacco Sci., 22: 131-304.

Gurcan, N., D. Erbas, E. Ergen, A. Bilgerhan, S. Dundar, A. Aricioglu et al., 1998. Changes in blood haemorheological parameters and submaximal exercise in trained and untrained subjects. N Physiol Res., 47: 23-27.

Halliwell, B., 2001. Role of free radicals in the neurodegenerative diseases: therapeutic implications for antioxidant treatment. Drugs Aging, 18: 685-716.

Higuchi, T., F. Omata, K. Tsuchihashi, K. Higashioka, R. Koyamada, S. Okada, 2016. "Current cigarette smoking is a reversible cause of elevated white blood cell count: Cross-sectional and longitudinal studies"Preventive medicine reports, 4: 417-22.

Ho, C.H., 2004. White blood cell and platelet counts could affect whole blood viscosity. J Chin Med Assoc, 67(8): 394-397.

Hunter, K.A., P.J. Garlick, I. Broom, S.E. Anderson, M.A. McNurlan, 2001. Effects of smoking and abstention from smoking on fibrinogen synthesis in humans. Clin Sci., 100: 459-465.

Ishizaka, N., Y. Ishizaka, E. Toda, R. Nagari, K. Koike, H. Hashimito and M. Yamakado, 2007 Relationship between smoking, WBC count and metabolic syndrome in Japanese women. Diabetes Res. Clin.Pract., 78: 72-76.

Koc, H., A. Tekin, A. Ozturk, R. Saraymen, K. Gokdemir, M. Elioz, M. Afr, 2012. Microbiol. Res., J. 6(9): 2027-2032.

Kume, A., T. Kume, K. Masuda, F. Shibuya, H. Yamzaki, 2009. Dose-dependent effect of cigarette smoke on blood biomarkers in healthy volunteers: Observations from smoking and non-smoking. Journal of Health Sciences, 55(2): 259-264.

Loimaala, A., R. Rontu, I. Vuori, M. Mercuri, T. Lehtimaki, A. Nenonem, M.G. Bond, 2006. Blood leukocyte count is a risk factor for intimamedia thickening and subclinical carotid atherosclerosis in middleaged men. Atherosclerosis, 188: 363-369.

Mahapatra, S.K., S. Das, S.K. Dey and S. Roy, 2008. Smoking induced oxidative stress in serum and neutrophil of the university students. Al Ameen J. Med. Sci., 1(1): 20-31.

Malenica, M., B. Prnjavorac, T. Bego, T. Dujic, S. Semiz1, S. Skrbo, A. Gusic, A. Hadzic and A. Causevic, 2017. "Effect of Cigarette Smoking on Haematological Parameters in Healthy Population"MED ARCH.; 71(2): 132-136

Milman, N., N.A. Pedersen, 2009. Blood hemoglobin concentrations are higher in smokers and heavy alcohol consumers than in nonsmokers and abstainers should we adjust the reference range. AnnHematol., 88(7): 687-694.

Moxley, R.T., P. Brakman, T. Astrup, 1970. Resting levels of fibrinolysis in blood in inactive and exercising men. J ApplPhysiol., 28: 549-552. 
Pasupathi, P., G. Saravanan and J. Farook, 2009. Oxidative Stress Bio Markers and Antioxidant Status in Cigarette Smokers Compared to Nonsmokers. J. Pharm. Sci. \& Res., 1(2): 55-62.

Pittilo, R.M., 2000. Cigarette smoking, endothelial injury and cardiovascular disease. Int J ExpPathol., 81: 219-230.

Ravala, M and A. Paula, 2010. Cerebral venous thrombosis and venous infarction: Case report of a rare initial presentation of smoker's polycythemia case rep. Neurol., 2: 150-156.

Rosner, B., 2000. Fundamentals of Biostatistics.5th edition. Pacific Grove, CA: Duxbury Press;

Tiel, D., E.L. Van, H.M.P. Peeters, A.H. Smit, J.D.N. Nagelderke, M.V.A.J. Loon, et al., 2002. Quitting smoking may restore hematological characteristics within five years. Ann Epidemiol., 12: 378-388.

Tsiara, S., M. Elisaf, D.P. Mikhailidis, 2003. Influence of smoking on predictors of vascular disease. Angiology, 54: 507-530.

Waters, D., J. Lesperance, P. Gladstone, S.T. Boccuzzi, T. Cook, R. Hudgin, G. Krip, L. Higginson, 1996. Effects of cigarette smoking on the angiographic evaluation of coronary atherosclerosis: a Canadian Coronary Atherosclerosis Intervention Trial (CCAIT) substudy. Circulation, 94: 614-621.

William, D., F. McArdle, I. Kath, L. Victor, Katch, 2000. "Essential exsercise physiology". Lippincott Williams \&Wilkins, Second edition.

Wood, P., 1994. Physical activity, diet, and health: independent and interactive effects. Med Sci Sports Exerc, 26: 838-843. 